\title{
Monitoria na escola do campo: aluno ajudando aluno no processo de ensino-aprendizagem da Matemática
}

\section{Tutoring in the rural school: student helping student in the teaching-learning process of \\ Mathematics}

Dieyson Câmara

Universidade Tecnológica Federal do Paraná (UTFPR), Programa de Mestrado Profissional em Matemática em Rede Nacional (PROFMAT), Pato Branco, PR, Brasil https: //orcid.org/0000-0001-5927-8099, dieyson. camara@hotmail.com

Rômel da Rosa da Silva Universidade Tecnológica Federal do Paraná (UTFPR), Departamento de Matemática, Programa de Mestrado Profissional em Matemática em Rede Nacional (PROFMAT), Pato Branco, PR, Brasil

https://orcid.org/0000-0003-3206-9320, romelsilva@utfpr.edu.br

\section{Informações do Artigo}

\section{Como citar este artigo}

CÂMARA, Dieyson; SILVA, Rômel da Rosa da. Monitoria na escola do campo: aluno ajudando aluno no processo de ensino-aprendizagem da Matemática. REMAT: Revista Eletrônica da Matemática, Bento Gonçalves, RS, v. 7, n. 1, p. e2008, 20 abr. 2021. DOI: https://doi.org/10.35819/ remat2021v7i1id4213

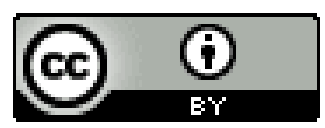

Histórico do Artigo

Submissão: 27 de maio de 2020.

Aceite: 10 de novembro de 2020 .

\section{Palavras-chave}

Monitoria

Escola do Campo

Ensino de Matemática

\section{Resumo}

Este artigo apresenta uma compilação dos resultados obtidos na pesquisa de Câmara (2017), a qual investigou o uso da atividade de monitoria envolvendo alunos de séries distintas, no Ensino Fundamental, na escola do campo. Foram realizados quatro encontros de monitoria nos quais alunos do nono ano auxiliaram alunos do sexto ano na resolução de uma série de exercícios envolvendo as quatro operações básicas com números naturais. A análise dos dados coletados revelou que a atividade de monitoria foi bem-aceita pelos alunos e que houve aprendizagem efetiva, de onde podemos concluir que a monitoria pode ajudar no processo de ensino e aprendizagem de Matemática na escola do campo. 


\begin{tabular}{ll} 
Abstract \\
This paper presents a compilation of the results obtained by Câmara (2017) \\
in his research, which investigated the use of tutoring activities involving \\
students from different grades in middle school and focused on the rural \\
educational system. Four tutoring meetings were held and, during said \\
Keywords & meetings, ninth grade students helped sixth grade students solve a series \\
Tutoring & of activities involving the four basic operations with natural numbers. The \\
Rural School & analysis of the collected data revealed that the activity was well accepted \\
Mathematics Teaching & and that there was effective learning, which leads us to conclude that the \\
& tutoring activity can help with the process of teaching and learning mathe- \\
& matics in rural education. \\
\hline
\end{tabular}

\section{Introdução}

A educação do campo foi por séculos negligenciada na dicotomia campo cidade. Silva Júnior e Borges Netto (2011, p. 46), no que se refere à educação rural, escreveram: "[...] observamos que foi historicamente relegada a espaços marginais nos processos de elaboração e implementação das políticas educacionais na realidade brasileira". Segundo Silva e Silva Júnior (2012), esse fato fica evidenciado nos textos constitucionais, uma vez que a educação rural não foi mencionada nas constituições até 1891.

O cenário começa a mudar ao final do século XX; um marco para isto é o $1^{\circ}$ Encontro Nacional de Educadoras e Educadores da Reforma Agrária (1ํENERA), ocorrido em 1997. Para Munarim (2008), o Manifesto das Educadoras e Educadores da Reforma Agrária ao Povo Brasileiro, lançado no 1ํㅡㄹ ENERA, é a certidão de nascimento do movimento por ele intitulado Movimento de Educação do Campo no Brasil. Movimento de cunho sociopolítico e de certa renovação pedagógica que luta, dentre outras coisas, pela educação do povo do campo:

[...] grupos identitários, cuja produção da existência se dá fundamentalmente a partir da relação com a natureza, direta ou indiretamente, vivam essas populações nas sedes de pequenos municípios, ou nas florestas, ou nas ribanceiras, ou nas propriedades de agricultura familiar, ou nos assentamentos da reforma agrária, ou nas áreas remanescentes de quilombos, ou em outros espaços sócio-geográficos de igual apelo cultural e de produção da vida (MUNARIM, 2008, p. 59).

No ano seguinte, em 1998, ocorreu a 1aㅡ Conferência Nacional por uma Educação Básica do Campo, a qual forçou a mudança do termo, antes "rural" (escola rural), para agora "do campo" (escola do campo), não apenas por um jogo de palavra, mas sim, pela diferença de concepção.

De acordo com Sachs (2018, p. 406), “[...] a mudança seria tamanha que não 'suportaria' os mesmos termos como referência". Ainda segundo a mesma autora, (p. 406), "[...] a 'educação rural', 
carregada de descaso e subordinação ao capital, é substituída pela 'educação do campo' [...] a qual carrega diferentes preceitos políticos e pedagógicos". As mudanças, principalmente a partir dos meados da década de 1990, impulsionaram e impulsionam políticas públicas voltadas à educação do camponês, bem como as pesquisas em educação do campo.

No que diz respeito às pesquisas envolvendo a educação do campo, são claros os avanços, mas a produção científica nessa temática ainda é baixa. Barbosa, Carvalho e Elias (2014) realizaram uma análise das publicações científicas comunicadas nas primeiras 10 edições (1997-2010) do Encontro Nacional de Educação Matemática (ENEM) e constataram que apenas 0,3\% (aproximadamente) do total de trabalhos publicados no ENEM tratam da temática educação do campo.

Mais recentemente, Sachs (2018) apresentou um levantamento de publicações acadêmicas em um periódico, a saber no Boletim de Educação Matemática (BOLEMA), edições de 1985 a 2016 , em 12 edições do ENEM (1997-2016) e no de banco de teses da Coordenação de Aperfeiçoamento de Pessoal de Nível Superior (CAPES), período de 2005 a 2016. Sachs (2018, p. 419) destaca que "nos últimos anos, houve um aumento significativo de publicações que aproximam a educação do campo e a educação matemática [...]". Vemos este aumento de forma muito positiva, no entanto, os números ainda são baixos frente às décadas de abandono dos estudos da temática no Brasil e aos desafios da educação do campo.

Diante ao exposto acima: o histórico de anos de abandono no que diz respeito à educação do campo, com melhorias recentes, mas ainda iniciais, nos sentimos "obrigados" a dar mais visibilidade à pesquisa realizada durante o curso de Mestrado Profissional em Matemática em Rede Nacional (PROFMAT), defendida e apresentada na dissertação intitulada "Monitoria na Escola do Campo: Alunos Ajudando Alunos na Aprendizagem da Matemática” (CÂMARA, 2017).

O trabalho de pesquisa teve como objetivo avaliar possíveis contribuições da atividade de monitoria envolvendo alunos de anos distintos do Ensino Fundamental da escola do campo. Para isso, fizemos um teste piloto, no qual alunos do nono ano auxiliaram alunos do sexto ano na resolução de uma sequência de atividades distribuídas em quatro encontros de monitoria. Voltamos nossa atenção, em especial, para a análise dos pontos: conteúdos abordados; participação e percepção dos monitores; e participação e percepção dos alunos do sexto ano.

Os encontros de monitoria foram realizados no mês de julho de 2017, em uma escola do campo no interior da cidade de Capanema/PR. A referida escola fica na zona rural, a $14 \mathrm{~km}$ da cidade, e atende principalmente alunos da comunidade, essa, essencialmente rural, com baixo poder 
aquisitivo, onde muitos agricultores trabalham de forma braçal, acompanhados, às vezes, pelos filhos, alunos da escola, nessas atividades. A escola atende no período vespertino e, na época da pesquisa, estudavam nela cerca de 50 alunos, distribuídos em 4 turmas do Ensino Fundamental: 6º $7^{\circ}, 8^{\circ}$ e $9^{\circ}$ anos. No sexto ano estudavam 10 alunos, enquanto no nono, 15 alunos.

\section{Referencial teórico}

No que diz respeito à educação matemática, é notório o crescimento de trabalhos que relacionam as dimensões sociais, políticas e culturais do ensino com as práticas sociais dos próprios sujeitos. Nesse sentido, compartilhamos da postura de Roseira (2010, p. 50):

Admitir os aspectos sociais, culturais e históricos como imprescindíveis para entender a Matemática é considerá-la um construto do sujeito, não apenas no âmbito de sua individualidade, mas também no entendimento de um sujeito inserido em sua cultura, estabelecendo as relações sociais necessárias à sua sobrevivência, enfim, construindo sua história e a história de sua coletividade.

No tocante às publicações científicas entrelaçando educação matemática e educação do campo, destacam-se no Brasil as ligadas à etnomatemática e à matemática crítica. Sachs (2018), após um levantamento em publicações acadêmicas, apresenta quatro categorias, as quais focam aspectos importantes do currículo de uma escola do campo:

A primeira delas entende que é importante "partir da realidade" para chegar ao objeto matemático; a segunda sugere que sejam incluídos nos currículos os "saberes locais"; a terceira afirma que não deve haver especificidade no programa curricular de matemática dessas escolas; e, por fim, a quarta compreende que a escola deveria, também, oferecer uma formação técnica para o trabalho rural (SACHS, 2018, p. 404).

Desse modo, as atividades na escola do campo devem depender de cada escola, das características da microrregião onde ela está inserida, da evolução histórico-cultural, que em um processo de sedimentação dos conhecimentos gera os saberes locais, das atividades econômicas, enfim: de toda uma conjuntura, que é particular de cada região e acaba formatando o modo de vida do camponês presente em determinada localidade. Nesse sentido, vemos a etnomatemática como uma real possibilidade, pois considera aspectos sociais e culturais no ensino de Matemática.

A etnomatemática teve seus primeiros traços na década de 1970 e seu precursor foi o brasileiro Ubiratan D'Ambrosio, doutor em Matemática, professor emérito em várias universidades brasileiras. A teoria veio, segundo Costa (2014, p. 182), "[...] como uma espécie de crítica ao ensino tradicional da matemática e análise da sua aplicação em diversos contextos socioculturais". 
Para D’Ambrosio (2008) a definição de etnomatemática é muito difícil, uma explicação de caráter etimológico pode ser dada fracionando a palavra em três raízes: eteno correspondendo às diversidades dos ambientes; matema significando explicar, entender, ensinar, lidar com; tica corresponde a artes, técnicas. Desse modo, “[...] etnomatemática, que, portanto, significa o conjunto de artes, técnicas de explicar e de entender, de lidar com o ambiente social, cultural e natural, desenvolvido por distintos grupos culturais" (D'AMBROSIO, 2008, p. 8).

Segundo Passos (2008, p. 44), tanto a etnomatemática quanto a educação matemática crítica foram reações a um processo histórico:

A primeira reação foi simbolizada pela emergência das idéias trazidas pela Etnomatemática através da reivindicação de uma valorização das diferentes (etno) maneiras (tica) de interpretar a realidade (matema). Representando a segunda reação, a Educação Matemática Crítica pretendia inserir na escola discussões acerca dos papéis exercidos pela Matemática na sociedade.

Ole Skovsmose, um dos grandes nomes do movimento da educação matemática crítica, iniciou os estudos da temática quando convidado para participar do projeto "Educação Matemática e Democracia em Sociedades Altamente Tecnológicas”. Financiado pelo Conselho Dinamarquês de Pesquisa em Ciências Humanas, tinha como objetivo discutir Educação Matemática como parte de uma tentativa democrática em uma sociedade altamente tecnológica (PASSOS, 2008).

A educação crítica deu suporte às discussões da educação matemática crítica e, segundo Skovsmose (2001), a educação crítica tem três pontos-chave: envolvimento dos estudantes no controle do processo educacional; estudantes e professores devem estabelecer uma distância crítica do conteúdo da educação; o direcionamento do processo de ensino-aprendizagem a problemas.

Desse modo, influenciada pela educação crítica, a educação matemática crítica preconiza que deve ser atribuído a professores e estudantes uma competência crítica e esses, em conjunto, devem identificar e trabalhar com problemas sociais objetivamente existentes, relevantes para os alunos e para o processo educacional. A matemática escolar deve fomentar a construção da cidadania e competências.

Conforme expõe Pessôa e Damázio Júnior (2013, p. 83), é importante:

[...] desenvolver, através do ensino de matemática, um olhar crítico sobre as estruturas matemáticas que são colocadas na sociedade e que seja capaz de valorizar os vários conhecimentos matemáticos desenvolvidos por diferentes setores da sociedade é uma das principais preocupações da Educação Matemática Crítica. 
Nesse contexto, olhando em direção à escola do campo, compartilhamos das ideias de Lima e Lima (2013, p. 5): "O ensino deve priorizar o diálogo dos saberes escolares com a cultura, com o modo de vida do camponês e suas atividades produtivas, problematizando a realidade".

Passos (2008) explora e aponta conexões, no sentido de consonância e complementaridade, entre a etnomatemática e a educação matemática crítica, fato corroborado por Araújo (2009, p. 61), que afirma que dependendo da perspectiva que se adota, pode haver fortes relações entre a etnomatemática e a educação matemática crítica.

Como depreende-se da leitura de Tomaz e David (2008), uma das formas de desenvolver a criticidade, no sentido da educação matemática crítica, é por meio da interdisciplinaridade. O movimento da interdisciplinaridade nasceu na Europa, na década de 1960, e o eco de suas discussões, com distorções, chegou ao Brasil no final da década de 1960 (FAZENDA, 2008). De lá para cá, a teoria vem sendo discutida e aprimorada, mas não existe um consenso entre os pesquisadores sobre o que é interdisciplinaridade: "são muitas as concepções e o termo não parece apresentar um sentido único e preciso" (OLIVEIRA; SANTOS, 2017, p. 73).

Hilton Japiassu é um dos pioneiros dos estudos da interdisciplinaridade no Brasil. Oliveira e Santos (2017) abordam esse e outros autores de renome na área, e apresentam as distintas concepções, dos autores estudados, em torno do tema, evidenciando que as "concepções, embora distintas, convergem para a superação do ensino da fragmentação do conhecimento e a necessidade de diálogo por parte dos docentes" (OLIVEIRA; SANTOS, 2017, p. 73).

No tocante à atividade de monitoria na escola do campo, não encontramos, na literatura brasileira, obras específicas acerca dessa temática, no entanto, alguns trabalhos indicam a possível efetividade dela. Cunha Júnior (2017) apresenta resultados de um projeto envolvendo a investigação da atividade de monitoria em sala de aula, em um contexto escolar em nível Médio. De acordo com o autor, "[...] os resultados obtidos pelos alunos sugerem que a implementação dessas atividades obteve grande sucesso [...]" (CUNHA JúNIOR, 2017, p. 691). Em nível Fundamental podemos citar o trabalho de Santos (2018), o qual investigou o papel da monitoria como ferramenta de apoio pedagógico no ensino de Matemática. O autor discorre, "[...] essa prática da monitoria proporciona grandes benefícios que podem ser desfrutados por discentes, monitor e docente com o intuito de auxiliar e contribuir no desenvolvimento de um aprendizado mais significativo e prazeroso da Matemática" (SANTOS, 2018, p. 125). 
Motivadora, também é a tese de Silva (2014). Na pesquisa, investigou-se o uso de ambientes favoráveis, nos anos finais do Ensino Fundamental, com diálogo, interação e cooperação de diferentes sujeitos no contexto da aprendizagem da matemática escolar. A autora relata: "[...] muitas vezes fui surpreendida positivamente e me emocionei com os estudantes e seus processos de dialogar e aprender matemática [...] ficou muito clara a solidariedade dos estudantes [...]" (SILVA, 2014, p. 322). Ainda, segundo a autora, "[...] a maioria se envolveu efetivamente e cooperativamente com as aprendizagens dos colegas" (p. 322).

Vemos, na atividade de monitoria, como aqui proposta, um desses ambientes favoráveis, que possibilita diálogo, interação e cooperação.

\section{Metodologia}

Em um primeiro momento, buscamos determinar particularidades e necessidades; fizemos um levantamento bibliográfico, a fim de entender em que contexto histórico-social a escola do campo está inserida na sociedade brasileira. A segunda etapa foi identificar o referencial teórico que nos pautasse no processo de ensino-aprendizagem. Tivemos como guia a etnomatemática, mas essa "conversou" com a interdisciplinaridade e a matemática crítica nas atividades propostas.

Após estas fases mais investigativas, voltamos nossos olhos para a situação da escola, identificando o panorama do andamento das atividades na instituição, em especial, das ligadas ao ensino de Matemática. Identificamos que um trabalho envolvendo monitoria com alunos do nono e do sexto ano e com o tema "operações com os números naturais" poderia ser promissor. Isso porque, na escola em questão, os alunos do sexto ano trabalham com números naturais e os do nono tem uma revisão sobre o assunto. Unimos as duas turmas em torno de um ponto matematicamente relevante a ambas e o tema central das atividades de monitoria foi "operações básicas, soma, subtração, produto e divisão com números naturais".

Definido o objeto de investigação, as turmas envolvidas e o tema dos encontros de monitoria, passamos para a fase da estruturação das atividades. A fim de levantar dados para posterior análise elaboramos: duas provas diagnósticas; quatro sequências de atividades, para serem realizadas nos encontros de monitorias; um pequeno questionário; e o caderno de campo. Descrevemos, na sequência, cada um dos referidos itens.

Na prova diagnóstica A, colocamos um problema envolvendo a pesca no Rio Iguaçu. Apresentamos um enunciado acerca da dinâmica das idas e vindas, deslocamentos, de um pescador 
ao longo do mês de Abril de 2017. Na sequência, são postas nove questões a serem respondidas, sendo a maioria delas baseadas no texto introdutório. Destacamos que o Rio Iguaçu é um dos principais rios da região, está próximo às moradias dos alunos e alguns camponeses utilizam a pescaria como fonte de renda.

A produção de leite é outra atividade geradora de renda comum na região. A prova diagnóstica $B$ traz um pequeno enunciado atrelado à produção de leite em uma chácara ao longo do mês de Fevereiro de 2017. Também colocamos nove questões, sendo a maioria delas relacionadas ao enunciado. Em ambas as provas diagnósticas, as questões envolveram as quatro operações básicas, soma, subtração, produto e divisão de números naturais.

As quatro atividades para os encontros de monitoria, assim como nas provas diagnósticas, exploraram as operações básicas com números naturais. Cada uma das atividades continha um texto introdutório e oito questões a serem respondidas, na maioria delas, necessitando buscar informações no texto apresentado.

O texto da primeira atividade, Atividade 1, localiza histórica e geograficamente a cidade de Capanema. Para a Atividade 2, apresentamos dados acerca da Usina Hidrelétrica do Baixo Iguaçu, em construção, na época, na cidade de Capanema, e considerada muito importante para a cidade e para a região, trazendo impostos e gerando empregos, sendo assunto comentado na comunidade onde os alunos estão inseridos.

As atividades 3 e 4 estão ainda mais próximas do dia a dia dos alunos. Na Atividade 3, descrevemos como um criador de gado pretende cercar uma área de pastagem retangular e exploramos essas informações nas questões da atividade, as quais, além de envolver as operações básicas com números naturais, trazem os conceitos de área, perímetro e unidades de medidas. Destacamos que a prática de construção de cerca é comum na região, muitos alunos têm em suas propriedades cercas para criação de gado.

$\mathrm{Na}$ Atividade 4, trazemos dados sobre o cultivo de mandioca. As informações passam pela origem, clima para o bom desenvolvimento da planta, forma de cultivo, espaçamento entre plantas, colheita e preço pago ao produtor. Ressaltamos que na região a mandioca é cultivada tanto para consumo próprio, quanto para alimentação de animais e comercialização.

Em relação ao questionário, a ser respondido pelos alunos e alunos monitores, participantes da pesquisa, foi bastante simples, com apenas dois itens: 1) Cite os pontos positivos das atividades de monitoria; 2) Cite os pontos negativos das atividades de monitoria. Completou o conjunto de 
instrumentos de coleta de dados o caderno de campo, que podemos descrever basicamente como um bloco para anotações.

Estruturada a pesquisa, encaminhamos o projeto, via Plataforma Brasi ${ }^{1}$, para análise. Após aprovado, iniciou-se o contato com os discentes. Dos 15 alunos do nono ano, 8 aceitaram participar da pesquisa, como monitores. Já no sexto ano, a adesão foi total, os 10 alunos da turma aceitaram participar do trabalho, dessa forma, montou-se um grupo com 18 alunos colaboradores.

Após definida a equipe de trabalho, mas previamente às atividades de monitoria, o pesquisador Dieyson Câmara, reuniu-se, apenas, com os alunos monitores. Nesse encontro, foram discutidos os exercícios das quatro listas de atividades: destacamos que os alunos monitores tinham resolvido os exercícios previamente em casa. Após sanada todas as dúvidas, foram passadas algumas recomendações em relação aos procedimentos durante os encontros de monitoria, em especial, orientamos que eles não fornecessem a resposta das questões aos alunos, mas sim, ajudassem na interpretação, na efetivação dos cálculos matemáticos e sugerissem aos colegas ler mais de uma vez os enunciados. Destacamos que a conversa, a discussão na busca do entendimento e efetivação das tarefas, seria bem-vinda e poderia ser incentivada e promovida.

Também, antes dos encontros de monitoria, os alunos do sexto ano realizaram a primeira prova diagnóstica, sorteada dentre as duas avaliações de antemão preparadas. Os alunos realizaram a prova individualmente, sem consulta e tiveram, para isso, 45 minutos. Após esses dois momentos, que envolveram separadamente participantes da pesquisa do nono e do sexto ano, deuse início os encontros de monitoria propriamente dito.

No primeiro encontro de monitoria o pesquisador fez a apresentação entre os alunos, distribuiu o material com a Atividades 1, recomendou que os alunos do sexto ano lessem e respondessem às questões com o máximo de empenho e que, em caso de dúvida, poderiam solicitar ajuda dos monitores, que se posicionaram no fundo da sala. Após cerca de 10 minutos, alguns alunos do sexto ano já solicitavam ajuda e era claro, aos olhos do pesquisador, o empenho de todos os participantes. Os estudantes do sexto ano mostravam interesse em responder às perguntas, os monitores, do nono ano, caminhavam entre as carteiras e ofereciam ajuda para os discentes do sexto ano. Os quatro encontros de monitoria, de 45 minutos cada, foram acompanhados pelo pesquisador, que

\footnotetext{
${ }^{1}$ A Plataforma Brasil é uma base nacional de registros de pesquisas envolvendo seres humanos. Ela permite que as pesquisas sejam acompanhadas em seus diferentes estágios - desde sua submissão até a aprovação final pelo Comitê de Ética e Pesquisa. Fonte: Disponível em: http://plataformabrasil.saude.gov.br/login.jsf Acesso em: 22 maio 2020.
} 
ficou no fundo da sala, para passar segurança e intervir caso houvesse necessidade. Não houve a necessidade de intervenções.

Cabe observar, que a menos das orientações prévias, iniciais, a dinâmica dos encontros foi conduzida pelos próprios alunos, não indicamos que o "aluno A" deveria ajudar/discutir com o "aluno B", tampouco impusemos que as discussões deveriam ser realizadas em dupla. Três ou mais estudantes poderiam trabalhar em conjunto, com grupos moldados e reformulados de acordo com o andamento das atividades e das decisões dos discentes, de modo que as relações entre os envolvidos foram se formando ao longo dos encontros de monitoria.

Os demais encontros seguiram, em termos de participação e motivação, o observado no primeiro encontro. No final do segundo encontro, alguns alunos questionaram se de fato teriam outras monitorias. Recebendo a confirmação a reação foi de comemoração, o que indica interesse na atividade. No terceiro encontro, os alunos do sexto ano estavam mais à vontade com os monitores, fato que foi bom para a atividade de monitoria. Em relação ao último encontro, destacamos que alguns discentes comentaram ajudar seus pais no cultivo da mandioca, contribuindo na interpretação, discussão e resolução das questões.

Na semana seguinte ao último encontro de monitoria, foi aplicada a segunda prova diagnóstica que, assim como na primeira avaliação diagnóstica, foi individual, sem consulta a material e com tempo para realização de 45 minutos.

Como último instrumento de coleta de dados, tivemos o questionário, entregue aos participantes para ser preenchido em casa e devolvido ao pesquisador dentro de sete dias. Todos os questionários foram devolvidos devidamente preenchidos.

Fechamos a presente seção comentando da análise dos dados coletados ela foi quantitativa quando contamos acertos, acertos parciais e erros, nas provas diagnósticas e nas listas de atividades; e qualitativa quando classificamos os erros em de interpretação ou de cálculo. Também foram qualitativas as análises do diário de campo e dos questionários preenchidos pelos alunos.

\section{Resultados e discussão}

As provas diagnósticas e as atividades realizadas foram analisadas, e erros e acertos, contabilizados. A categoria erro foi dividida em dois tipos: erro de interpretação e erro de cálculo. No segundo caso, a questão foi corretamente interpretada, mas a resposta não foi alcançada por falha 
na efetivação de alguma das quatro operações básicas. Para cada questão correta, atribuímos 1 ponto, para as com erro de interpretação, 0 ponto e questões com interpretação correta, mas com erro de cálculo, receberam 0,5 (meio) ponto. Isso facilitou a análise quantitativa utilizando gráficos.

A Figura 1 apresenta o quantitativo de acertos, por aluno, em cada um dos quatro encontros de monitoria. As letras A, B, C, D, E, F, G, H, I e J nomeiam os alunos do sexto ano participantes da pesquisa. Depreende-se do gráfico, alocado na Figura 11 que os monitores, embora auxiliassem os alunos, deram, a eles, autonomia, uma vez que não houve padronização de respostas, nem no número de acertos nas atividades. O que, para nós, é algo positivo, sinalizando que os monitores entenderam o papel, proposto pelos pesquisadores, a ser realizado por eles: ajudar, mas não resolver questões. Destacamos aqui, que o erro quando posteriormente tratado, digamos pelo professor, também pode gerar conhecimento. Segundo Cury (2019), a análise de erro é uma modalidade de ensino. Detectado dificuldades na aprendizagem, podemos discutir sobre elas, a fim de levar os alunos ao questionamento de suas próprias soluções, tornando o erro ferramenta no processo de ensino-aprendizagem.

Figura 1 - Acertos nas atividades de monitoria.

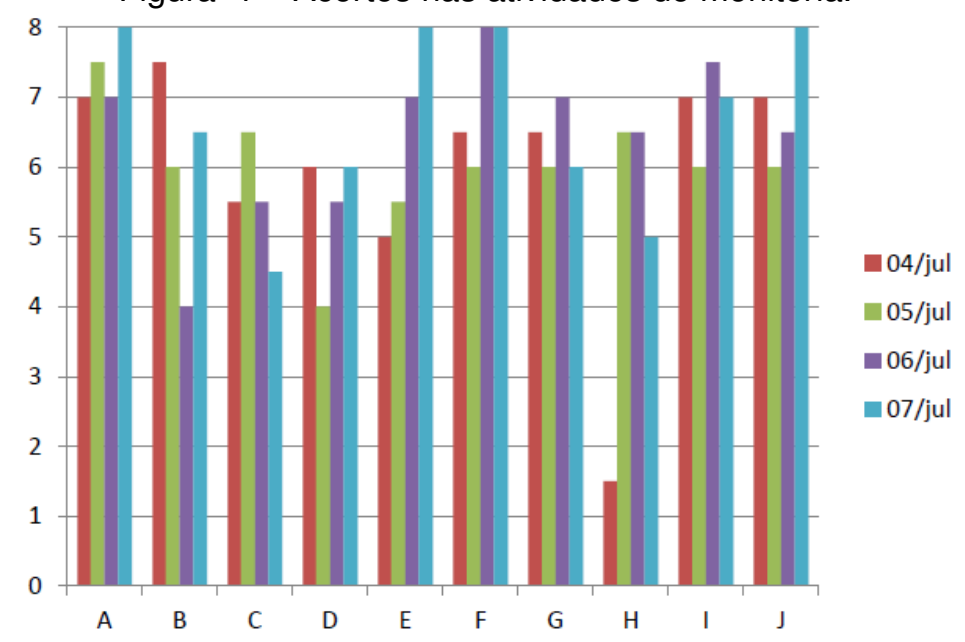

Fonte: Dados da pesquisa. Adaptado de Câmara (2017, p. 51).

A destacar ainda, em relação às resoluções das atividades realizadas nos encontros de monitoria, o fato de que o número de erros de interpretação foi ligeiramente maior do que números de erros de cálculo. Isso pode estar atrelado à estrutura das atividades, pois, em geral, para responder determinada questão, a busca das informações devia ser feita em um texto informativo e não no próprio enunciado da referida pergunta. Fugindo, assim, do mais usual, no entanto, aproximandose mais do dia a dia, onde as informações estão postas num contexto mais geral e devem ser interpretadas pelo cidadão. 
A Figura 2 revela o número de acertos nas duas provas diagnósticas e as datas marcam os dias de aplicação. Vemos, a partir da Figura 2, que em um pequeno intervalo de tempo houve um avanço significativo no desempenho da grande maioria dos alunos, indicando que de fato a atividade de monitoria foi produtiva. Destacamos que no período de 30 de junho a 10 de julho os alunos envolvidos na pesquisa não realizaram, no ambiente escolar, outras atividades ligadas à matemática, reforçando, assim, o elo entre a melhora de desempenho com as atividades realizadas durante a pesquisa, ou seja, aos encontros de monitoria.

É relevante observar que, na primeira prova diagnóstica, algumas respostas eram apresentadas sem nenhum cálculo ou argumento, apenas um número estava posto, que interpretamos como sendo a resposta, como foi o caso dos alunos $D, E$ e J, que não apresentaram cálculos em suas folhas de resposta. Se o número indicado correspondesse à solução do problema contamos como resposta certa. Na segunda prova diagnóstica ninguém deixou da apresentar cálculos básicos envolvendo números naturais, algo que pode ser considerado positivo se pensarmos além da simples contagem de erros e acertos.

Figura 2 - Acertos nas avalições diagnósticas.

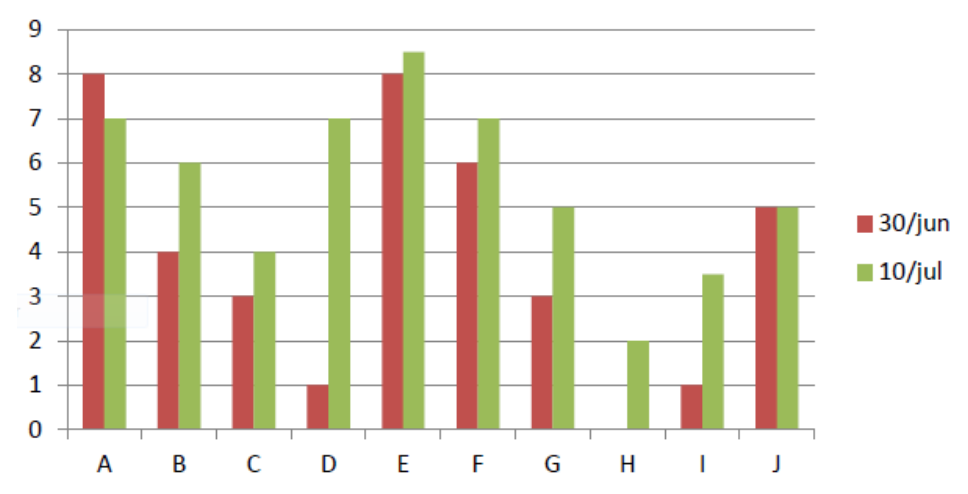

Fonte: Dados da pesquisa. Adaptado de Câmara (2017, p. 55).

Fazendo uma leitura mais teórica dos encontros de monitoria, podemos dizer que o aluno do sexto ano foi posto em uma situação de "crise'2, reagindo a esta, acaba por pôr o monitor em mesma situação. Agora com um propósito comum, aluno(s) e aluno(s) monitor(es) precisam dialogar, entender(em) e ser(em) entendido(s). O que pode contribuir para a formação de um cidadão mais crítico, como preconiza a educação matemática crítica.

\footnotetext{
${ }^{2}$ É preciso ler, interpretar e resolver as atividades. De forma crítica e por sua conta o discente deve avaliar se há, ou não, necessidade de pedir ajuda ao colega mais experiente, o monitor.
} 
Além disso, os discursos, entre alunos, transcendem a matemática: informações históricas, geográficas e culturais, postas nos textos introdutórios das atividades, precisam ser entendidas e fazem parte das discussões. Caracterizando, assim, mesmo que tenuemente, a interdisciplinaridade. Ademais, tratamos de questões próximas dos alunos, em alguns momentos, o conhecimento cultural do discente acabou sendo explorado, utilizado nos diálogos e na resolução dos problemas. Isso foi mais evidente na atividade envolvendo o cultivo da mandioca. Algumas informações sobre o cultivo da mandioca já faziam parte do conhecimento sociocultural do grupo e tal conhecimento foi utilizado, tanto para entender o conjunto de informações passadas, quanto para resolver as questões propostas. De certa forma, o passo um pouco mais curto dado pelo agricultor para ditar o espaçamento entre as plantas é uma unidade de medida explorada na atividade. Ficando, assim, bem caracterizada a etnomatemática no encontro.

Podemos ver, a partir da devolutiva dada pelos alunos no questionário, que a atividade diferenciada, embasada na etnomatemática, valorizando a comunidade local, foi bem avaliada pelos estudantes. Tivemos pontos positivos e pontos negativos, mas os negativos foram em número pequeno quando comparado aos positivos. Alguns alunos do sexto ano citaram que um monitor não auxiliava corretamente por não ter domínio suficiente do conteúdo. Um aluno argumentou que os encontros deveriam ter mais de 45 minutos. Estes foram os únicos dois problemas descritos pelos discentes do sexto ano.

No nono ano, de negativo, tivemos: menções à falta de leitura dos alunos do sexto ano - uma resposta dada foi "alguns alunos não liam o que estava no enunciado e ia direto para as perguntas, o que dificultava o entendimento da questão"; um aluno comentou não ter gostado de precisar chamar a atenção quanto à conversa. Mas a resposta que se repetiu algumas vezes foi: "acho que não teve pontos negativos".

Os pontos positivos vieram num volume muito maior: quanto aos alunos de sexto ano um escreveu, "Eu achei que foi legal e fiz muitos amigos e também aprendi um monte", outro, "[...] aprendi coisas boas que não sabia e tinha dificuldade e treinei as contas". Muitos alunos elogiaram a atenção dos monitores, sendo comum, também, resposta envolvendo: ter gostado da atividade; feito novos amigos; aprendido coisas que não sabia; e praticado as operações matemáticas.

Os alunos monitores mencionaram ter gostado da atividade citando várias razões, e com motivos recorrentes: fizemos novos amigos; precisamos nos colocar na posição do professor; aprendemos melhor o conteúdo; foi uma atividade diferente; e quem ensina aprende mais ainda. Boa parte dos alunos relatou ter gostado da atividade e espera realizar novamente atividade como essa. 
Uma monitora escreveu: "[...] Apesar de ter sido só quatro encontros, acho que eles conseguiram aprender algo [...] com a pesquisa só pude ter mais certeza de que serei professora [...]". Outra em um trecho: "Gostei de fazer a monitoria pois foi algo novo e diferente. Achei que tanto os alunos do 6ำ ano quanto nós do $9^{\circ}$ ano aprendemos muito, tanto explicando quanto resolvendo as questões".

Os poucos pontos negativos e a maciça maioria dos comentários positivos revela que a atividade de monitoria envolvendo alunos do nono e do sexto ano na escola do campo foi bemaceita pelos participantes. O teor das colocações indica que, de fato, houve aprendizagem dentro e fora da matemática e aponta que o sucesso pode estar atrelado não apenas à monitoria em si, mas também ao perfil das atividades elaboradas. Nas palavras, ajustadas, de um aluno participante da pesquisa, as questões eram interessantes, pois tratavam de assuntos "legais".

\section{Considerações finais}

São muitos os desafios no processo de ensino-aprendizagem, constantemente buscam-se formas de o tornar mais atraente e efetivo. Apresentamos, neste trabalho, uma alternativa: a monitoria ligada à etnomatemática. Com a monitoria, buscamos pôr os estudantes em posição de destaque, de certa forma, atribuindo a eles, mais responsabilidade, pois, são agora os protagonistas. Juntamos a isso, no intuito de facilitar as discussões e deixar os encontros mais atraentes e produtivos, uma estrutura de atividades que valoriza as questões locais e os seus saberes.

Com as provas diagnósticas, percebemos a evolução dos discentes, e por meio dos questionários, captamos a percepção dos alunos e alunos monitores em relação à atividade. Analisando provas e questionários podemos concluir que houve aprendizagem matemática, criação e/ou fortalecimento de laços de amizade, satisfação em ambos os grupos ao desenvolver as atividades, ambiente colaborativo, alunos sentindo-se valorizados.

Acrescentando que não encontramos, na literatura brasileira, artigos referentes à monitoria na escola do campo, acreditamos, que embora pontual, nossa proposta é pioneira, e a pesquisa traz contribuições positivas para a educação matemática, em especial, na escola do campo.

\section{Referências}

ARAÚJO. J. L. Uma Abordagem Sócio-Crítica da Modelagem Matemática: a perspectiva da educação matemática crítica. Alexandria: Revista de Educação em Ciência e Tecnologia, v. 2, n. 2, p. 55-68, 1 jul. 2009. Disponível em: 
https://periodicos.ufsc.br/index.php/alexandria/article/view/37948. Acesso em: 7 abr. 2021.

BARBOSA, L. N. S. C. de; CARVALHO, D. F.; ELIAS, H. R. As relações estabelecidas entre o cotidiano camponês e a aula de matemática: análise da produção científica em 10 edições do Encontro Nacional de educação Matemática. EM TEIA: Revista de Educação Matemática e Tecnológica Iberoamericana, v. 5, n. 1, p. 1-21, 2014. Disponível em: https://periodicos.ufpe.br/revistas/emteia/article/view/2209. Acesso em: 7 abr. 2021.

CÂMARA, D. Monitoria na Escola do Campo: Alunos Ajudando Alunos na Aprendizagem da Matemática. Orientador: Rômel da Rosa da Silva. 2017. 102 f. Dissertação (Mestrado Profissional em Matemática) - Programa de Mestrado Profissional em Matemática em Rede Nacional, Universidade Tecnológica Federal do Paraná, Pato Branco, 2017. Disponível em: https://repositorio.utfpr.edu.br/jspui/bitstream/1/3000/1/PB_PROFMAT_M_C\%C3\%A2mara\% 2C\%20Dieyson_2017.pdf. Acesso em: 7 abr. 2021.

COSTA, F. J. M. da. Etnomatemática: metodologia, ferramenta ou, simplesmente, etnorrevolução? Zetetiké, Campinas, SP, v. 22, n. 42, p.181-196, jul./dez. 2014. DOI: https://doi.org/10.20396/zet.v22i42.8646571.

CUNHA JÚNIOR, F. R. da. Atividades de monitoria: uma possibilidade para o desenvolvimento da sala de aula. Educação e Pesquisa, São Paulo, v. 43, n. 3, p. 681-694, jul./set. 2017. DOI: https://doi.org/10.1590/s1517-9702201707154754.

CURY, H. N. Análise de erros: O que podemos aprender com as respostas dos alunos. 3. ed. Belo Horizonte: Autêntica, 2019.

D’ AMBROSIO, U. O Programa Etnomatemática: uma síntese. Acta Scientiae, Canoas, v. 10, n. 1, p. 7-16, jan./jun. 2008. Disponível em: http://www.periodicos.ulbra.br/index.php/acta/article/view/74. Acesso em: 7 abr. 2021.

FAZENDA, I. C. A. Interdisciplinaridade: História, teoria e pesquisa. 15. ed. Campinas: Papirus, 2008.

LIMA, A. S. de; LIMA, I. M. da S. Educação matemática e educação do campo: desafios e possibilidades de uma articulação. EM TEIA: Revista de Educação Matemática e Tecnológica Iberoamericana, v. 4, n. 3, p. 1-10, 2013. Disponível em: https://periodicos.ufpe.br/revistas/emteia/article/view/2218. Acesso em: 7 abr. 2021.

MUNARIM, A. Trajetória do movimento nacional de educação do campo no Brasil. Educação, Santa Maria, v. 33, n. 1, p. 57-72, jan./abr. 2008. Disponível em: https://periodicos.ufsm.br/reveducacao/article/view/19/0. Acesso em: 7 abr. 2021.

OLIVEIRA, E. B. de; SANTOS, F. N. dos. Pressupostos e definições em interdisciplinaridade: diálogo com alguns autores. Revista Interdisciplinaridade, São Paulo, n. 11, p. 73-87, out. 2017. Disponível em:

https://revistas.pucsp.br/index.php/interdisciplinaridade/article/view/34709. Acesso em: 7 abr. 2021.

PASSOS, C. M. dos. Etnomatemática e Educação Matemática Crítica: conexões teóricas e práticas. Orientadora: Jussara de Loiola Araújo. 2008. 154 f. Dissertação (Mestrado em Educação) - Programa de Pós-Graduação em Educação, Faculdade de Educação, Universidade Federal de Minas Gerais, Belo Horizonte, 2008. Disponível em: https://www.ime.usp.br/ brolezzi/carolinepassos.pdf. Acesso em: 7 abr. 2021. 
PESSÔA, E. B.; DAMÁZIO JÚNIOR, D. Contribuições da Educação Matemática Crítica para o processo de materacia nas séries iniciais do Ensino Fundamental: um olhar através dos Parâmetros Curriculares Nacionais. Revista BoEM, Joinville, v. 1, n. 1, p. 76-98, jul./dez. 2013. Disponível em: https://www.revistas.udesc.br/index.php/boem/article/view/3953. Acesso em: 7 abr. 2021.

ROSEIRA, N. A. F. Educação matemática e valores: das concepções dos professores à construção da autonomia. Brasília: Liberlivro, 2010.

SACHS, L. Currículo de Matemática na educação do campo: panoramas e zoons. Zetetiké, Campinas, SP, v. 26, n. 2, p. 404-422, maio/ago. 2018. DOI: https://doi.org/10.20396/zet.v26i2.8647567.

SANTOS, A. G. dos. Monitoria como ferramenta auxiliar para aprendizagem da disciplina Matemática: uma análise de sua implementação no Ensino Fundamental. Saberes Docentes em Ação, Maceio, v. 4, n. 1, p. 125-142, abr. 2018. Disponível em:

http://www.maceio.al.gov.br/wp-content/uploads/2018/04/pdf/2018/04/ MONITORIA-COMO-FERRAMENTA-AUXILIAR-PARA-APRENDIZAGEM-DA-DISCIPLINA-MATEM\%C3\% 81TICA-UMA-AN\%C3\%81LISE-DE-SUA-IMPLEMENTA \%C3\%87\%C3\%830-NO-ENSINO-FUNDAMENTAL-ID . pdf. Acesso em: 7 abr. 2021.

SILVA, E. B. da. O Diálogo entre Diferentes Sujeitos que Aprendem e Ensinam Matemática no Contexto Escolar dos Anos Finais do Ensino Fundamental. Orientador: Cristiano Alberto Muniz. 2014. 341f. Tese (Doutorado em Educação). Programa de Pós-Graduação em Educação, Faculdade de Educação, Universidade de Brasília, Brasília, 2014. Disponível em: https://repositorio.unb.br/handle/10482/16403. Acesso em: 7 abr. 2021.

SILVA JÚNIOR, A. F. da; BORGES NETTO, M. Por uma educação do campo: percursos históricos e possibilidades. Entrelaçando: Revista Eletrônica de Culturas e Educação, n. 3, ano 2, p. 45-60, nov. 2011.

SILVA, M. V.; SILVA JÚNIOR, A. F. Políticas educacionais para a educação do campo: dimensões históricas e perspectivas curriculares. Revista HISTEDBR On-line, Campinas, n. 47, p. 314-332, set. 2012. DOI: https://doi.org/10.20396/rho.v12i47.8640054.

SKOVSMOSE, O. Educação Matemática Crítica: A Questão da Democracia. Campinas: Papirus, 2001.

TOMAZ, V. S.; DAVID, M. M. M. S. Interdisciplinaridade e aprendizagem da Matemática em sala de aula. 1. ed. Belo Horizonte: Autêntica, 2008. 